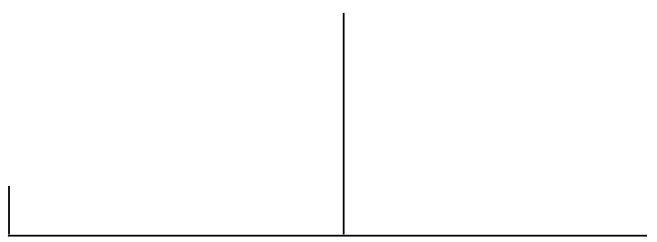

Rev. Latinoam. Psicopat. Fund., São Paulo, v. 15, n. 5, p. 138-170, março 2012

\title{
A psicopatologia da afetividade: aspectos conceituais e históricos*
}

\author{
German E. Berrios
}

Os transtornos do afeto não contribuíram muito para a definição diagnóstica da doença mental, e sua descrição fenomenológica nunca alcançou a riqueza da psicopatologia da percepção ou da cognição. Esse artigo mostra como o papel subordinado desempenhado pela afetividade na concepção ocidental do homem conduziu a uma visão inicial, mas persistente, da doença mental como um distúrbio exclusivo do intelecto. Tentativas dos psiquiatras do século XIX de contestar essa noção foram apenas parcialmente bem-sucedidas, devido às dificuldades de manejo conceitual da maior parte dos comportamentos afetivos e da redundância terminológica que isto engendrava. Esses esforços foram frustrados pelo renascimento do Associacionismo, o surgimento dos experimentos de localização cerebral, a definição periferialista das emoções e, finalmente, pelos desdobramentos do darwinismo. Como resultado, não se desenvolveu nenhuma psicopatologia autônoma da afetividade. O eventual reconhecimento dos assim chamados transtornos "primários" do humor não levou, contudo, a um refinamento na semiologia das próprias experiências. Isso foi impedido pelo uso dos substitutos descritivos comportamentais ou pelas descrições metapsicológicas do afeto como uma forma de energia ou como uma força pulsional. Nenhum desses desenvolvimentos contribuiu para a descrição clínica dos transtornos de humor.

Palavras-chave: Transtornos do humor - história, psicopatologia - história, psicologia - história, emoções

* Publicação original: The psychopatology of affectivity: conceptual and historical aspectos, Psychological Medicine, n. 15, p. 745-758, 1985.

Tradução de Lazslo A. Ávila e revisão técnica de Ana Maria G. R. Oda. 
HISTÓRIA DA

PSICOPATOLOGIA,

POR GERMAN E.

BERRIOS

\section{Introdução}

A semiologia dos transtornos afetivos tem sido sempre o primo pobre da psicopatologia descritiva e, como consequencia, os sintomas pertencentes a essa categoria não têm sido plenamente utilizados na definição da doença mental (Bash, 1955; Schneider, 1959; Jaspers, 1963; Hamilton, 1974; Sharfetter, 1980). Os psiquiatras do século XIX enfatizaram os transtornos de pensamento em detrimento da patologia da afetividade (Griesinger, 1867; Ribot, 1897; Bianchi, 1906; Bleuler, 1906; Chaslin, 1912).

De certo modo, isso não surpreende. Essa relativa negligência simplesmente reflete visões anteriores do papel subordinado desempenhado pelas emoções na definição do homem. Então, como agora, dificuldades conceituais atrapalharam os esforços dos clínicos em desenvolver uma linguagem descritiva. Os "sentimentos" eram considerados como estados mentais enganosos brevemente representados por algumas manifestações comportamentais mal definidas (White, 1967; Ryle, 1949). O caráter intratável das emoções engendrou um palimpsesto terminológico que até hoje permanece opaco e multívoco (Ketal, 1975; Owens \& Maxmen, 1979; Pollit, 1982). Houve até mesmo discordância quanto ao que contaria como relato válido de uma emoção (Sartre, 1939; Bedford, 1964).

É um fato histórico que as "paixões" desempenharam, desde a época dos gregos (até o final do século XVIII), um papel secundário na definição da natureza humana (Dodds, 1951; Landman, 1958; Pigeaud, 1981). É menos óbvio se isso poderia ser considerado como a causa das dificuldades conceituais mais recentes. Seja como for, essa relegação trouxe em sua esteira diversas consequencias indesejáveis. A mais importante, desde o ponto de vista psiquiátrico, tem sido a perspectiva exclusivamente intelectualística da 
loucura, mantida até muito recentemente na cultura ocidental (Roccatagliata, 1973; Colloque International de Bruxelles, 1976; Simon, 1978).

Ainda outra consequencia dessa negligência secular foi o fracasso, por parte dos psicólogos do século XIX, de virem em ajuda dos psiquiatras quando eles tentaram fazer uso das emoções na definição da doença mental (Berrios, 1984a). Por exemplo, a tentativa de alguns associacionistas (por exemplo, Herbart) (Mischel, 1973) de acomodar constructos não cognitivos não teve sucesso. É uma sugestão plausível a de que isso possa ser devido ao instrumental conceitual insuficiente do associacionismo (Warren, 1921; Hoeldtke, 1967; Bricke, 1974).

A inadequação do tratamento médico e psicológico dos sentimentos tornou-se uma fonte de mal-estar durante a primeira parte do século XIX. Isto não é surpreendente durante um período histórico em que a civilização europeia estava, em todas as outras esferas, plenamente consciente da importância da afetividade para o comportamento humano. Na ocasião, este mal-estar levou à reação teórica da segunda metade do século. Isso se cristalizou no trabalho fenomenológico inicial de Brentano (Rancurello, 1968), nos hipnotizadores (Barrucard, 1967), em Janet (Schwartz, 1955) e em Freud (Ellenberger, 1970).

A abordagem molecular (reducionista), iniciada pelo associacionismo e desenvolvida ao máximo por Ribot e Wundt, estendeu-se até o século XX. Na psiquiatria, por exemplo, pode ainda ser encontrada em áreas tão distantes como a terapia cognitiva da depressão, com sua ênfase no aspecto intelectualista (cognitivo) da emoção (Gelder, 1983) ou na terapia comportamental (Erwin, 1978) ou na assim chamada abordagem psicofisiológica, segundo a qual uma construção hipotética, chamada "excitação", desempenha um papel tão importante como o estado experiencial em si (Lader, 1975).

Outra consequência da negligência da patologia das emoções tem sido o desenvolvimento gradual de uma série de termos genéricos para nomear classes de "sintomas emocionais", cujos membros têm, na maioria dos casos, permanecido indefinidos (por exemplo, "transtornos de afeto" ou de "humor" ou "distúrbios emocionais" ou "equivalentes afetivos" [Fonseca, 1963]). Palavras antigas também foram readotadas - melancolia, mania, ansiedade, fobia, pânico (Lewis, 1967; Giudicelli, 1983; Errera, 1962), ou inventadas - disforia (Liebowitz \& Klein, 1979), alexitimia (Lesser \& Lesser, 1983), distimia (Akiskal, 1983), aprosodia (Ross \& Mesulam, 1979), e anedonia (Watson et al., 1970; Harrow et al., 1977; Koh et al., 1981).

Parece claro que, embora esses termos denominassem determinados estados subjetivos, eles não se originam no mesmo campo semântico. Eles parecem referir-se às variações qualitativas ou quantitativas em alguma função fundamental de menor nível. Mais frequentemente, no entanto, eles são descritos como com- 


\begin{tabular}{c|c} 
HISTÓRIA DA \\
PSICOPATOLOGIA, \\
POR GERMAN E. \\
BERRIOS \\
\hline
\end{tabular}

postos de supostos ingredientes primários. A composição ou relevância dessas misturas permanece incerta.

Do ponto de vista histórico, alguns destes termos se tornaram conchas vazias após as teorias envolvidas em sua geração terem desaparecido. Ocasionalmente, novas teorias têm se ocupado deles, como é o caso com os termos melancolia e depressão. Este último é particularmente interessante já que sua força semântica levou, desde o século XIX, a uma série de hipóteses etiológicas. Em todos esses casos, um princípio de deficiência, envolvendo um substrato químico ou psicológico, tem recebido destaque (Griesinger, 1867; Kowalewski, 1886; Ribot, 1897).

Não é de todo implausível acreditar que a semiologia dos transtornos de humor poderia ter sido diferente hoje se maior ênfase tivesse sido colocada sobre a natureza primária do afeto, e menor atenção tivesse sido dada à causalidade especulativa ou às origens somáticas. As abordagens "fenomenológicas" e estruturais tentaram corrigir essa anomalia, mas suas propostas alcançaram apenas uma audiência limitada (Scheler, 1923; Alonso, 1976; Piaget, 1981).

\section{Aspectos conceituais \\ A natureza imponderável dos sentimentos}

Estados afetivos consistem de experiências que são difusas em sua natureza e, portanto, temporalmente mal definidas (Kenny, 1963). São claramente reconhecíveis quando inundam a consciência do sujeito, mas sua associação regular com desencadeantes e circunstâncias sociais não é clara (Schachter \& Singer, 1962). Não obstante estas dificuldades, o sujeito tem (em geral) sido convidado a apreender seus estados afetivos pela introspecção e, se possível, a nomear suas sensações ou imagens mediadoras (Ribot, 1897). Isso levou à afirmação tantas vezes repetida de que ele está em uma posição "privilegiada” como repórter. Esta visão do século XIX tem, no entanto, enfrentado dúvidas quanto: (a) a existência de um "espaço interior"; (b) a "utilidade" da introspecção; (c) a capacidade do sujeito separar estados mistos em seus componentes primários; e (d) a adequação do uso de palavras para nomear emoções (Bedford, 1964).

As novidades deste importante debate não atingiram de fato a psicopatologia clínica. Na prática psiquiátrica, espera-se que o doente mental descreva seu estado emocional, apesar do fato evidente de que ele é incapaz de comportar-se como um observador racional. Delírios, agitação e distrações nublam sua introspecção e distorcem seus relatos. O próprio transtorno de humor que ele é soli- 
citado a descrever pode constituir-lhe de fato uma nova experiência, tornando sua posição "privilegiada" irrelevante. Os médicos tendem a utilizar, de acordo com seu grau de sofisticação, uma série de parâmetros para localizar e interpretar os estados de humor: duração, intensidade, qualidade, saliência, intencionalidade (objeto), agradabilidade, variação diurna, interferência com competências psicossociais, controle comportamental etc. O paciente com doença aguda é, então, solicitado a pontuar ou descrever seu humor em termos de alguns desses parâmetros.

Desde que os entrevistadores clínicos são regularmente bem-sucedidos na avaliação dos estados patológicos de humor, não é razoável acreditar que o relato pelo paciente de seu estado interior não possa ser de fato o único dado relevante. É mais plausível sugerir que os dados, tais como história, sintomas simultâneos, personalidade, comportamento não verbal e "credibilidade" psicopatológica desempenhem um papel decisivo. De fato, a evidência histórica mostra que, desde o século XIX, estados de humor foram avaliados e classificados, levando em consideração aspectos somáticos, comportamentais e metapsicológicos (Ribot, 1897; Störring, 1907).

É claro também que relatos "fenomenológicos" ou avaliação do humor só funcionam porque o médico e o paciente geralmente compartilham um sistema de sinais para os sentimentos vinculados à cultura (Krueger, 1928). Tanto a aprendizagem como os determinantes biológicos podem estar subjacentes à aquisição deste sistema de pistas (Mantegazza, 1878; Gruber, 1981; Darwin, 1872).

Uma análise histórica dos termos envolvidos na nomeação dos estados afetivos pode ser justificada pela suposição plausível de que as palavras representam esforços seculares para dar sentido a experiências subjetivas e seus acompanhantes comportamentais, e, portanto, poderiam capturar características invariantes do afeto humano, muitas vezes mascaradas pelo ruído cultural. Por exemplo, as emoções têm ao longo dos séculos sido tratadas como constructos de nível mais baixo do que, digamos, o "humor" ou os afetos. Daí a definição deste último ter incluído a referência tanto às experiências interiores quanto às pistas culturais e comportamentais (Donegan, 1968; Weiskrantz, 1968).

\section{A terminologia}

Humor, afeto, sentimento, emoção, paixão, agitação e propensão (inter alia) constituem uma família de termos com um referente proteiforme. Eles têm variadas origens etimológicas e resultam de diferentes épocas históricas. A visão de que eles são membros de uma linguagem psicológica "dramática", consagrando a sabedoria dos séculos, continua a ser atraente, mas sem comprovação (Deleule, 1969).

Rev. Latinoam. Psicopat. Fund., São Paulo, v. 15, n. 1, p. 138-170, março 2012 


\begin{tabular}{c|c} 
HISTÓRIA DA \\
PSICOPATOLOGIA, \\
POR GERMAN E. \\
BERRIOS \\
\hline
\end{tabular}

Emoção e paixão foram habitualmente distinguidos de humor, afeto e sentimento em termos de critérios, tais como duração, intensidade, polaridade, insight, saliência, associação com um objeto interno ou externo, sensações corporais e força motivacional. Emoção e paixão são definidos como estados sentimentais que são de curta duração, mais ou menos intensos, salientes e relacionados a um objeto reconhecível (Ribot, 1897); emoção e paixão (a última dos quais é uma versão intensa da anterior) são consideradas como acompanhadas por mudanças corporais e, portanto, possuem propriedades motivacionais (Leeper, 1948).

Humor e afeto, por outro lado, são definidos como estados mais duradouros e sem objeto, capazes de fornecer uma espécie de tonalidade de sensação de fundo para o indivíduo (Ketal, 1975; Owens \& Maxmen, 1979). Sobre estas emoções de humor básico valores congruentes (sintímicos) ou incongruentes (catatímicos) podem ser sobrepostos (Dash, 1955). O afeto também é considerado como "disposicional" na sua natureza, isto é, estar com "afeto A" significa que, se certas condições forem cumpridas, o sujeito se comportará de uma forma particular (Ryle, 1949). O tom e a consistência das experiências e das formas comportamentais que normalmente são chamados de humor e afeto são, provavelmente, controlados por variáveis neuroendocrinológicas, submetidas elas próprias aos controles genético e ambiental. Tentativas foram feitas para redefinir o afeto como uma categoria simbólica, estreitamente relacionada com os sistemas de ação do indivíduo (Siomopoulos, 1983; Green, 1977). Estes pontos de vista podem ser muito abstratos para serem aproveitados na psicopatologia descritiva cotidiana.

Sentimento é o termo mais amplo e mais abstrato de toda a família (Fellner von Feldegg, 1900; Gardiner, 1906; Washburn, 1906; Claparède, 1928; BeebeCenter, 1951). Definido de modo negativo, refere-se aos aspectos da experiência humana que não são nem cognitivos, nem volitivos. Quando as sensações são provocadas por um estímulo externo, têm consequências informativas e não informativas. Essa última, ou seja, a capacidade de causar uma modificação na experiência subjetiva do indivíduo, constitui o "sentimento".

Há um certo desacordo sobre a contribuição proporcional para a formação e definição de um sentimento acarretada pelo estímulo externo e pelo sujeito sensível. Há também desacordo sobre a existência de sentimentos "elementares", e quando isso é aceito há falta de acordo sobre a natureza do mecanismo de como os sentimentos elementares vêm a formar estados emocionais complexos (por exemplo, ver a alegoria da estátua de Condillac (Condillac, 1947). 


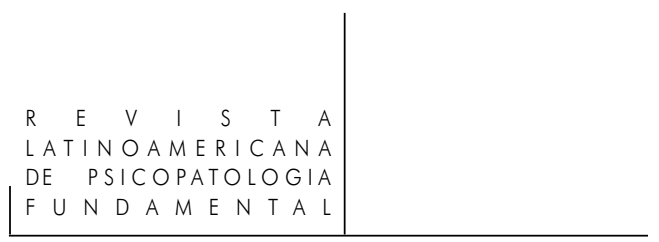

\section{Aspectos históricos}

\section{As paixões e a natureza do homem}

As paixões desempenharam um papel secundário no desenvolvimento da visão ocidental do homem. Tanto Platão (Dodds, 1951; Simon, 1972-1973; Solmsen, 1983) quanto Aristóteles (Lloyd, 1968; Fortenbaugh, 1975) consideravam a razão como sua característica definidora: ela era o instrumento do conhecimento e a garantia da liberdade ética. Daí sua ausência ou obliteração não podia deixar de levar ao erro e ao mal. Neste contexto contemplativo, as paixões representavam o principal agente de perturbação e caos. Esta visão teve que ser reconciliada com a crença de que as paixões constituiriam a parte animal do homem e, como tal, a fonte de seus impulsos e criatividade.

Esta ambivalência foi resolvida aceitando-se a existência de sentimentos (e experiências relacionadas), mas em uma capacidade subordinada ou "reduzida". Não é uma coincidência que desde então, e até o final do século XVIII, as emoções foram consideradas seja como um resíduo da sensação ou como um componente da volição, mas nunca como entidades em seu próprio direito (Gardiner et al., 1937). Assim, alguns consideraram os sentimentos como um subproduto da sensação e, portanto, como ontologicamente dependentes dos estímulos sensoriais, outros como não mais do que a preparação ou palco motivacional de uma volição. Mesmo filósofos da "Psicologia das faculdades mentais", como Reid (1969), reconheceram apenas poderes "intelectuais" e "ativos" na mente humana e incluíram as emoções entre estes últimos.

A primeira revisão importante dessas opiniões foi devida a Tomás de Aquino (Gardair, 1892; Monahan, 1935; Koninck, 1947; Simmonnet, 1983). Ele sugeriu que o estudo psicológico das paixões deveria começar pelo exame do comportamento cotidiano. Identificou as funções biológicas (por exemplo, crescimento, reprodução) e relacionais (por exemplo, a percepção sensorial, a locomoção), às quais o homem compartilha com os animais, e as distinguiu das faculdades cognitivas e apetitivas que eram exclusivas do homem. Ele reconheceu 11 funções apetitivas e as dividiu em duas classes: concupiscível e irascível. As paixões ou funções apetitivas eram a expressão dos "poderes" da alma, a qual era independente do corpo. Três importantes consequências derivaram de sua abordagem original: macroconceitos afetivos podem servir bem como unidade primária de análise; sentimentos estão intimamente relacionados às representações ou estruturas internas, e sua definição não necessariamente inclui conceitos corporais.

Descartes modificou este ponto de vista (Descartes, 1967; Kenny, 1968), definindo as paixões como "percepções, sentimentos ou emoções da alma que são 


$\mid$\begin{tabular}{c} 
HISTÓRIA DA \\
PSICOPATOLOGIA, \\
POR GERMAN E. \\
BERRIOS \\
\hline
\end{tabular}

especialmente relacionados a ela, e que são causados, mantidos e fortalecidos por alguns movimentos dos espíritos" (Descartes, 1967, p. 344). Embora esta definição ainda enfatize a natureza especial dos macroconceitos afetivos, ela desafia a visão das emoções como fenômenos desencarnados; de acordo com Descartes, as manifestações corporais devem ser incluídas na definição do sentimento (Weckowicz \& Liebel-Weckowicz, 1982). Sua visão da alma, como uma substância ontologicamente separada do corpo, levou, contudo, a uma negligência do componente somático dos sentimentos. Ela também deu origem ao chamado problema mente-corpo que viria a reverberar bastante no século XIX (Bynum, 1976). O subjetivismo cartesiano, no entanto, encorajou a visão das emoções como funções mentais independentes. Este processo culminou no trabalho de Kant no final do século XVIII (Buchner, 1897; Leary, 1978; Hilgard, 1980).

Embora o ponto de vista das paixões como perturbadoras do homem tenha sido posta em questão durante o século XVIII, para muitos ela ainda permaneceu como a doutrina aceita (Fulcher, 1973). Rousseau considerava as paixões como depositárias naturais da bondade e como representando o lado mais puro do homem (Gardiner et al., 1937; Riese, 1965). As distorções na compreensão do homem, criadas pelo intelecto "civilizado", só poderiam ser corrigidas, de acordo com ele, atendendo ao chamado das paixões. A consequência direta desta mudança "copernicana" é a crença romântica de que o homem aprende certos conceitos como a beleza das emoções e não da razão. Finalmente as emoções tinham adquirido um papel epistemológico (Abbagnano, 1961).

Tanto a medicina romântica quanto a positivista, durante o início do século XIX, laboriosamente procuraram integrar as paixões no conceito de doença (Riese, 1960; Pigeaud, 1980). Por exemplo, Comte caracterizava a loucura como um "excès de subjectivité" (Arbousse-Bastide, 1972). Nesta matéria, Lewes (1878, p. 217) escreveu: “'Agir par affection, et sentire pour agir': tal é o lema de seu sistema [Comte], o que indica a predominância dada ao emotivo sobre o meramente intelectual - em oposição à velha psicologia que sempre subordinou as emoções ao intelecto."

Durante o século XIX, o papel da emoção na psicopatologia tornou-se claro: ela poderia causar ou resultar da doença mental. O papel causal foi, no entanto, o mais antigo (Sauri, 1969) e acarretou durante este período a opinião de que a manipulação das emoções poderia ter valor terapêutico, o que viria a ser chamado de "tratamento moral" (Tissot, 1865; Colonna d'Istra, 1913; Carlson \& Droga, 1960; Bynum, 1964; Ey, 1978; Postel, 1979; Baguenier-Desormeaux, 1983). Esquirol propôs, já em 1805, uma descrição lúcida dessa perspectiva (Esquirol, 1980).

Discussões anteriores e os fatos sobre os quais elas estão baseadas mostram a relação entre as emoções e a insanidade; elas indicam melhor do que qual- 
quer definição o que significa o "tratamento moral". Se é essencial provocar choques violentos e excitar esta ou aquela emoção para controlar o lunático... não é menos importante ser gentil e afável para com ele. (p. 82)

\section{Paixões como causas da loucura}

É plausível sugerir que a crença antiga de que as paixões perturbavam a cognição está relacionada à igualmente antiga visão de que elas causam a loucura. Na cultura grega, a excitação afetiva, culminando na irracionalidade, era considerada um mecanismo comum de insanidade (Heiberg, 1927; Dodds, 1951; Drabkin, 1955). Essa visão permaneceu praticamente inalterada durante todo o período medieval (Jackson, 1972; Kroll, 1973; Neugebauer, 1979), durante o Renascimento (Colloque Internacional de Bruxelles, 1976) e nos tempos modernos até o século XIX (Rosen, 1968; Jobe, 1976; MacDonald, 1981; Conry, 1982; Foucault, 1954, 1972; Sauri, 1969; Pigeaud, 1980; Sass, 1983).

Os mecanismos precisos pelos quais as paixões induziriam à loucura raramente foram descritos em qualquer detalhe. Funções mentais mediadoras, tais como a "imaginação" (Balan, 1972; McMahon, 1976; Fischer-Homberger, 1979) e construções hipotéticas como a "reação" (Starobinski, 1977) foram, no entanto, frequentemente mencionadas. Há algumas evidências de que o conceito de "imaginação" possa ser um precursor da noção atual de "psicogênese" (Deerborn, 1937; Lewis, 1972).

A visão naturalista das paixões iniciada por Descartes se cristalizou na literatura médica só no final do século XVIII. Alexander Crichton (1798) resumiu assim:

... as paixões devem ser consideradas de um ponto de vista médico como parte de nossa constituição, que devem ser examinadas com o olhar do historiador natural, e o espírito e a imparcialidade do filósofo. Não é preocupação deste trabalho se as paixões devem ser consideradas afeições naturais ou artificiais, morais ou imorais. Elas são fenômenos ... e produzem constantes efeitos em nossa estrutura corpórea ... produzem efeitos benéficos e prejudiciais sobre as faculdades da mente. (v. 2, p. 97)

Não está claro por que essa nova visão das paixões como fenômenos naturais não incentivou os clínicos a desenvolverem uma psicopatologia descritiva da afetividade. Parece que o principal obstáculo era ainda a visão transmitida da loucura como um deslocamento do intelecto. Em nenhum lugar isso é mais claro do que na oposição dos alienistas, no início do século XIX, à existência de uma "monomania afetiva" (Kageyama, 1984). 


\begin{tabular}{c|c} 
HISTÓRIA DA \\
PSICOPATOLOGIA, \\
POR GERMAN E. \\
BERRIOS \\
\hline
\end{tabular}

A visão recebida de loucura

A definição de loucura herdada pelo século XIX era de natureza intelectualista. Irracionalidade e distúrbios comportamentais francos têm sido, desde os tempos dos gregos, duas características centrais da loucura (Dodds, 1951; Roccatagliata, 1973; Simon, 1978; Sarantoglou, 1980). Paranoia, frenesi, melancolia, mania e letargia foram definidas nestes mesmos termos (Heiberg, 1927; Drabkin, 1955; Berrios, 1981a).

A melancolia, por exemplo, foi definida como uma mistura de irracionalidade e expressão reduzida de comportamento (Starobinski, 1962; Flashar, 1966). Tristeza, embora ocasionalmente mencionada, não pode ser vista como tendo constituído um aspecto diagnóstico necessário ou suficiente. Esta visão da melancolia, totalmente diferente da atual, manteve-se inalterada até Galeno e depois até o período moderno (Colloque Internacional de Bruxelles, 1976; Jobe, 1976; Ciangler-Mundwiller, 1979; Jackson, 1983a).

A Anatomia da melancolia (Burton, 1883) e outros escritos do período ilustram bem isso (Jackson, 1980; MacDonald, 1981). Burton menciona a tristeza e o abatimento como acompanhamentos habituais da melancolia, mas também as obsessões, os delírios, o comportamento suicida e as queixas hipocondríacas. Ele considerava essas últimas não como complicações secundárias, mas como sintomas primários da melancolia. Na verdade, ele definiu como melancólico qualquer distúrbio mental caracterizado por um exagero de função, não importando se envolvesse ou não a vida afetiva (Evans, 1944).

Apesar da evidência histórica adequada em favor de uma ruptura conceitual na história da palavra melancolia, alguns historiadores clínicos ainda sentem a necessidade de assegurar uma linha evolutiva direta entre estes velhos conceitos e seu uso atual. Essa confusão resulta, em parte, do fato de que a palavra melancolia adquiriu pelo menos dois significados por volta deste período: um uso popular relacionado ao suicídio, à tristeza e à nostalgia (Rosen, 1975; Colloque Internacional de Bruxelles, 1976; MacDonald, 1981), e um uso técnico, que permaneceu fiel às especulações teóricas antigas e considerava a melancolia como uma forma de insanidade delirante (Jackson, 1983b). Psiquiatras do começo do século XIX comentaram acerca destes dois significados: "A palavra melancólico, consagrada na linguagem vulgar como o nome para a tristeza comum (tristesse) deveria ser deixada para os moralistas e poetas" (Esquirol, 1976, p. 78).

Frenesi, paranoia, letargia e mania também foram definidos, ao lado da melancolia, em termos de desordem intelectual (Heilberg, 1927; Drabkin, 1955; Roccatagliata, 1973; Simon, 1978). A visão intelectualista da insanidade recebeu um acréscimo de vida de John Locke (1690, Livro II, capítulo xi, parágrafo 13): 
... em suma, o defeito nos idiotas [naturals] parece advir da falta de velocidade, atividade e movimento nas faculdades intelectuais, pelo que eles são privados de raciocínio: enquanto os loucos [madmen], por outro lado ... não me parece terem perdido a faculdade de raciocínio: mas eles unem algumas ideias muito erradamente, as confundem com verdades. (Locke, 1690, Livro II, capítulo xi, parágrafo 13)

Há alguma evidência histórica para sugerir que John Locke possa ter sido influenciado nisso por Thomas Willis, cuja palestras em Oxford ele assistira (Dewhurst, 1980; Conry, 1982). Segundo essa visão, a loucura seria uma forma aberrante de associação de ideias. Distúrbios emocionais não desempenhariam nenhum papel em sua definição, seja como causas ou como sintomas. Na verdade, os sentimentos foram considerados por Locke apenas como um subproduto das sensações e ideias (Gardiner et al., 1937). Mas, mais importante, esta definição colocava a insanidade sob a tutela teórica e a proteção do associacionismo.

\section{Mudanças na visão recebida de loucura}

Mudanças teóricas e as demandas clínicas da nova medicina, no entanto, conduziram a esforços para revisar a visão intelectualista da insanidade no início do século XIX. Quatro desses fatores históricos serão discutidos brevemente: (1) o estabelecimento da afetividade como uma função mental autônoma na psicologia; (2) a progressão dos sentimentos para o topo de todas as qualidades humanas, na sequência do exercício de glorificação das emoções iniciado pelo movimento do Romantismo; (3) a compreensão de que a descrição intelectualista da insanidade era clinicamente demasiado restritiva; (4) o desenvolvimento de uma ciência dos sinais e sintomas clínicos.

\section{(1) A autonomia funcional da afetividade}

Durante o início do século XIX, a Psicologia das faculdades mentais se desenvolveu como uma alternativa psicológica ao associacionismo (Albrecht, 1970; Werlinder, 1978). Sua importância conceitual alcançou reconhecimento tardio (Fodor, 1983). Filósofos escoceses do Common Sense contribuíram para as suas bases fundamentais (Klein, 1970; Brooks, 1976), assim como a decisão eventual de Kant de apoiar um modelo tripartite da mente (Buchner, 1897; Leary, 1978; Hilgard, 1980). A Psicologia das faculdades não só forneceu para a frenologia suas bases conceituais (Lanteri-Laura, 1970; Cantor, 1975; Cooter, 1976) como também incentivou o trabalho posterior sobre a localização cerebral (Hécaen \& Lanteri-Laura, 1977).

De acordo com a Psicologia das faculdades mentais, a afetividade constitui uma faculdade primária, autônoma e irredutível da mente. Esta independência re- 


\begin{tabular}{c|c} 
HISTÓRIA DA \\
PSICOPATOLOGIA, \\
POR GERMAN E. \\
BERIOS \\
\hline
\end{tabular}

cém-encontrada em breve encorajou a sugestão de que os afetos poderiam ser, como as outras faculdades, suscetíveis a patologias primárias (Falret, 1864). Uma consequência direta dessa visão foi a aceitação gradual da existência de uma forma "emocional" ou "afetiva" de insanidade. Foram feitas tentativas para redefinir a melancolia para que ela se encaixasse na nova categoria. Este processo foi concluído no final do século. Nesse meio tempo, houve grande resistência à mudança (Kageyama, 1984).

Esquirol, por exemplo, tentou enfatizar o papel da tristeza no desenvolvimento da melancolia (ele cunhou o termo lipemania), mas afinal recaiu no conceito de loucura parcial (monomania) (Esquirol, 1976; Kageyama, 1984). Heinroth (1975) foi muito mais direto:

A presença de uma ideia fixa não significa que a doença seja uma afetação do intelecto, o intelecto é o mero servo da disposição doentia [...] a ideia fixa pode não estar presente, mas a melancolia permanece o que é: a depressão da disposição, a retirada em si mesmo, o desprendimento do mundo externo. (p. 190)

(2) Os sentimentos e o movimento Romântico

A glorificação dos sentimentos é uma das características centrais do Romantismo (Borgese, 1934; Lovejoy, 1960). Sua ênfase na experiência subjetiva como fonte de conhecimento estético encorajou o desenvolvimento da introspecção e, posteriormente, da noção de consciência psicológica (Boring, 1953; Danzinger, 1980). Este impulso no sentido do mentalismo provocou uma mudança da atitude médica quanto à definição da doença. Mais importante, causou uma redefinição dos conceitos tradicionais de "sinal" e "sintoma" (Barthes, 1972; King, 1968; Laín Entralgo, 1978; Lopez Piñero, 1983).

A psiquiatria também respondeu a essas mudanças, e os distúrbios da experiência subjetiva começaram a ser adicionados à sintomatologia da loucura (Berrios, 1981b; Riese, 1960; Pigeaud, 1980). Em um sentido geral, psicólogos e psiquiatras, como Maine de Biran (Delacroix, 1924; Drovet, 1968), Royer-Collard (Swain, 1978) e Moreau de Tours (Bollote, 1973) tornaram possível a incorporação do subjetivo na psiquiatria (Riese, 1960; Pigeaud, 1980). Complexas experiências interiores foram minuciosamente descritas, simplificadas e catalogadas em conformidade com o tratamento analítico da doença e suas manifestações, exigidas pela filosofia da ideologia (Rosen, 1946).

\section{(3) As limitações clínicas da visão herdada}

A visão intelectualista da loucura, embora em consonância com a epistemologia empirista do período, era de limitado uso clínico. No caso, o seu papel principal foi, provavelmente, o de facilitar o desenvolvimento do conceito de "insanidade parcial". Este termo teve pelo menos três significados durante o iní- 
cio do século XIX: ele poderia se referir às formas mais leves da doença, ao envolvimento de uma faculdade, ou ao fato de que os delírios se concentravam em um tópico particular. Durante este período, esse último transformou-se no termo délire exclusif (Kageyama, 1984); suas origens, no entanto, podem ser atribuídas a séculos anteriores. Por exemplo, Hartley (1834, p. 252) escreveu: "Observa-se que as pessoas loucas muitas vezes falam racional e consistentemente sobre os assuntos que aparecem, contanto que o tema isolado que mais os afeta seja mantido fora da vista." O conceito de loucura parcial também foi utilizado por médicos para proteger o papel da psiquiatria nos tribunais (Walker, 1968; Jackson, 1983a; Delkeskamp, 1977).

A relevância clínica da definição intelectualista foi desafiada no início do século XIX (Pinel, 1809):

Podemos admirar com justiça os escritos de Locke e mesmo assim afirmar que sua visão da mania está errada quando ele considera a mania como inseparável dos delírios [...] Eu costumava pensar da mesma forma, mas tenho ficado surpreso ao encontrar pacientes sem comprometimento da compreensão que são vítimas de ataques de excitação como se apenas as faculdades afetivas estivessem envolvidas. (p. 155-156)

Prichard (1835) adotou uma perspectiva semelhante:

Desde a época do Sr. Locke tem sido costume observar que pessoas insanas pensam corretamente a partir de premissas erradas [...] esta é uma apreensão muito limitada da insanidade e apenas abrange uma entre as várias formas de desarranjo mental. (p. 3)

Heinroth (1975) foi igualmente crítico da opinião de que os distúrbios mentais se originariam apenas da esfera do pensamento (insanidade ideativa e nocional): "Na verdade essas condições são meramente ideias abstratas e unilaterais, aventadas pela primeira vez por Locke" (p. 73).

\section{(4) O novo descritivismo}

A necessidade de descrever de forma confiável os sinais e sintomas era uma exigência conceitual da visão anatomoclínica da doença (Laín Entralgo, 1978; Lopez Piñero, 1983). A busca por mudanças morfológicas para combinar com estes sinais clínicos só foi bem-sucedida em outras áreas da medicina que não a psiquiatria (Lopez Piñero, 1983). Descritivismo sem anatomia, apesar do trabalho muito citado de Bayle sobre a paralisia progressiva do insano, foi a base epistemológica da medicina psicológica (Berrios, 1984a).

Além das exigências teóricas, as necessidades práticas também foram importantes a este respeito. Por exemplo, o envolvimento gradual dos médicos na direção dos asilos ocasionou novas necessidades descritivas, na medida em que, 


\begin{tabular}{c|c} 
HISTÓRIA DA \\
PSICOPATOLOGIA, \\
POR GERMAN E. \\
BERRIOS \\
\hline
\end{tabular}

como médicos oficiais, eram legalmente intimados a manter bons registros clínicos.

Igualmente importante para o desenvolvimento do descritivismo foi o fato de que o trabalho no hospital psiquiátrico e a manutenção de registros permitiu a observação de coortes de pacientes e, portanto, a análise longitudinal dos próprios sintomas (Ackerknecht, 1967). A introdução da dimensão temporal em psiquiatria (Del Pistoia, 1971) levou, no final do século [XIX], ao desenvolvimento da noção de "cronicidade" e sua ampla utilização como critério diagnóstico (LanteriLaura, 1972).

A nova abordagem analítica causou, então, a fragmentação das categorias clássicas (por exemplo, mania, melancolia, demência etc.) (Berrios, 1984a). Os velhos diagnósticos qualitativos deram lugar a uma abordagem mais quantitativa e a doença mental passou a ser definida como um conjunto de sintomas elementares. Algumas dessas redefinições foram baseadas em análises estatísticas das doenças (Berrios, 1984b).

\section{A semiologia da afetividade}

Resta explicar por que, apesar de todas essas mudanças favoráveis, os transtornos afetivos não desempenharam um papel importante na nova semiologia psiquiátrica. Durante o século XIX, psicólogos e filósofos acharam difícil superar a complexidade inerente dos sentimentos. Eles continuaram aberta ou veladamente suas tentativas de reduzir o comportamento afetivo, seja à cognição ou à volição (Rochoux, 1842; Jacques, 1875; Rosmini Serbati, 1888; Höffding, 1892; Wundt, 1897).

Os psiquiatras, por sua vez, consideraram os transtornos clínicos do humor como carentes de saliência e estabilidade. Indicadores comportamentais confiáveis para aferir sua presença ou instrumentos para medir sua intensidade não estavam disponíveis (Delasiauve, 1861; Soury, 1883). Mesmo os autores que desenvolviam a Psicologia das faculdades mentais, como Benjamin Rush, compartilhavam essa dificuldade (Noel \& Carlson, 1973). Carlson et al. afirmaram: "Rush tem pouco a dizer das paixões consideradas intrinsecamente. Seu tratamento é principalmente ocasional, onde as paixões estão associadas com outras faculdades, operações e doenças" (Rush, 1981, p. 460). Pinel (1809) foi igualmente parcimonioso a este respeito, apesar de sua crítica declarada ao ponto de vista intelectualista de Locke sobre a loucura.

Outra ilustração da dificuldade geral encontrada no tratamento clínico das paixões é fornecida pelos escritos de Esquirol. O título de sua tese era: "As paixões como causas, sintomas e meios de tratamento da doença mental" (Esquirol, 
1980). No mesmo texto, no entanto, ele não conseguiu desenvolver uma semiologia da afetividade. Mais surpreendentemente, o seu conceito de lipemania, que se destinava (como a palavra indica) a fazer do transtorno de humor o sintoma central, sublinhou o caráter "parcial" dos pensamentos delirantes (isto é, a monomania) (Delasiauve, 1851; Kageyama, 1984). Feuchtersleben (1847), apesar de sua inclinação psicodinâmica, definiu a melancolia em termos idênticos. Até mesmo um escritor idiossincrático como Broussais (1828) priorizou os aspectos corporais das paixões e subscreveu uma visão intelectualista da insanidade. Laycock $(1840,1860)$ enfatizou o aspecto fisiológico das "emoções e paixões", e sua lista de macroconceitos afetivos não é convincente. Bucknill \& Tuke (1858) não dedicaram nenhuma seção separada para os transtornos do afeto, que são discutidos no capítulo sobre a melancolia.

Curiosamente, Griesinger (muitas vezes acusado de antipsicologismo) foi um dos primeiros a lidar com as "anomalias do sentimento", em uma seção separada que ele intitulou "Distúrbios fundamentais da doença mental" (Griesinger, 1867). Falret (1854) tentou uma abordagem semelhante, e incluiu o "desarranjo das emoções" como uma subseção de sua "sintomatologia geral da insanidade". Seu tratamento do tema é, no entanto, insubstancial, o que não é surpreendente tendo em vista sua crença de que nenhuma faculdade pode tornar-se prejudicada isoladamente, isto é, o que foi chamado de princípio da solidariedade das faculdades mentais (Falret, 1864, 1866). Morel (1860) incluiu em seu livro um apêndice sobre "sintomas originados nas funções afetivas" e se esforçou em vão para definir "sentimentos, instintos etc.".

\section{A oportunidade perdida}

Durante a segunda metade do século XIX as chances de desenvolver uma psicopatologia descritiva do afeto foram ainda mais reduzidas devido a três mudanças ideológicas: (1) o darwinismo (Mackenzie, 1976); (2) o desenvolvimento de uma visão periferialista das emoções (Gardiner et al., 1937); e (3) os estudos de localização cerebral (Young, 1970; Hécaen \& Lanteri-Laura, 1977).

\section{(1) $O$ darwinismo}

O modelo de evolucionismo de Darwin voltou a sublinhar a velha crença de que o homem compartilha a função emocional com os animais inferiores (Darwin, 1872; Gruber, 1981). Também encorajou a visão de que as emoções representam programas comportamentais estereotipados (Barnet, 1962). Não é de estranhar, portanto, que as emoções passassem a ser consideradas como respostas primitivas, e que uma maior ênfase fosse colocada na análise da "expressão" eviden- 


\begin{tabular}{c|c} 
HISTÓRIA DA \\
PSICOPATOLOGIA, \\
POR GERMAN E. \\
BERIOS \\
\hline
\end{tabular}

te, com uma relativa negligência da experiência subjetiva. A atitude da visão evolucionista para com o descritivismo foi bem representada por Coupland (1892):

... a principal dificuldade para elucidar as emoções consiste no fato de que a maior parte é devida aos antecedentes históricos registrados nos organismos suscetíveis, mas pouco às aquisições individuais. Nenhuma experiência do indivíduo pode dar conta da força ou da direção dos sentimentos. Se alguém colocasse em dúvida o efeito cumulativo e permanente das influências raciais, teria apenas que tentar explicar sem tal referência qualquer uma das paixões e afetos mais pronunciados. Não é surpreendente, portanto, que tão pouco progresso tenha sido feito neste departamento da psicologia, devido à excessiva confiança no método introspectivo, um método que não leva mais longe do que a descrição. (p. 40)

Ribot (1897) escreveu do mesmo modo, castigando a teoria "intelectualista" e se alinhando com a "escola fisiológica", de acordo com a qual "todos os estados de sentimento (estão conectados) com condições biológicas” (p. vii). Lloyd Morgan (Richards, 1977) fez o mesmo: "Eu acho que a psicologia comparativa pode razoavelmente supor que em toda a gama da experiência sensorial, comum aos homens e aos animais, seus estados emocionais são da mesma natureza que os nossos" (Morgan, 1903, p. 365).

\section{(2) A visão periferialista}

Segundo essa visão, as emoções representam o eco subjetivo de alterações no sistema nervoso autônomo. Esse reducionismo a mecanismos fisiológicos incentivou a reanálise da subjetividade emocional em termos de sensações que chegam. Ziehen (1909), por exemplo, escreveu:

A psicologia tradicional considerava as emoções como a manifestação de uma faculdade especial independente da alma. Kant coloca as sensações de prazer e dor ... entre a faculdade cognitiva e a faculdade (volitiva) apetitiva ... em última análise o tom emocional de todas as ideias pode ser reduzido ao tom emocional das sensações. (p. 174)

Perspectivas periferialistas desta natureza (James, 1891; Gardiner et al., 1937), sem dúvida, contribuíram para o desenvolvimento do behaviorismo e dos vários estudos fisiológicos das emoções, mas fizeram pouco para a semiologia do afeto. Esta última exigia uma análise continuada da qualidade da experiência subjetiva baseada na suposição de que distinções genuínas poderiam ser feitas dentro do campo geral da afetividade. 


\section{(3) Localização cerebral}

O trabalho sobre a localização cerebral, apesar de toda sua importância para o desenvolvimento da neuropsicologia, não serviu tanto para as emoções, na medida em que concentrou-se na fala, na percepção e no movimento (Tizard, 1959; Meyer, 1974). Questões sobre a localização cerebral das emoções raramente foram feitas e, quando o foram, a resposta usual era uma referência ao sistema ganglionar ou nervoso simpático (Carpenter \& Power, 1876). Autores como Mairet (1883), que tentou localizar a afetividade no lobo temporal, descobriam que seu trabalho clínico e experimental caía em ouvidos surdos. As referências ao sistema vegetativo eram ambíguas, já que este sistema tanto poderia ser considerado como um gerador de emoções como simplesmente um instrumento para a sua expressão (Morel, 1866; Luys, 1883).

Nessa situação, não foi um pesquisador experimental, mas um médico, que reafirmou a velha hipótese: se a loucura delirante "só pode ser explicada pela doença de uma parte causando desarranjo de algumas das faculdades intelectuais ... a doença em outra parte pode não perturbar o intelecto, mas os poderes ou propensões morais" (Hollander, 1901, p. 8). Este autor coletou da literatura cerca de cinquenta relatos sobre a neuropatologia da melancolia, mostrando lesão nos giros angular e supramarginal do lobo parietal; no entanto, ele não fez nenhuma menção ao trabalho seminal de Mairet (Berrios, 1985).

Os lobos frontais foram ocasionalmente mencionados em relação aos sentimentos (Meyer, 1974). Bianchi, por exemplo, relatou o trabalho experimental em macacos, mostrando as mudanças em emoções complexas após excisões no lobo frontal, embora sua metodologia tenha sido mais tarde criticada por Lashley (Hécaen \& Lanteri-Laura, 1977). Estes estudos de localização eram muito limitados no seu escopo para contribuir ao desenvolvimento de uma fenomenologia dos transtornos de humor.

\section{As consequências clínicas}

A abordagem reducionista mantida por psicólogos e neurocientistas experimentais durante este período mostrou-se inútil para o psiquiatra que tentava desenvolver uma semiologia dos afetos. A reação a esse estado de coisas veio de contextos separados. Uma delas foi a tentativa determinada de Brentano (Rancurello, 1968; Brentano, 1973; Fancher, 1977) e mais tarde de Ward (1889, 1919) para retornar a uma fenomenologia dos macroconceitos afetivos. Freud, em geral, seguiu este ponto de vista (Green, 1973; Laplanche \& Pontalis, 1973), mas, como Green (1977) corretamente disse, "[...] ele lutou com o problema do afeto toda a sua vida". Esta dificuldade, provavelmente, proveio do fato de que em seu sistema ele atribuiu um papel muito complexo para o afeto. Não só era 


\begin{tabular}{c|c} 
HISTÓRIA DA \\
PSICOPATOLOGIA, \\
POR GERMAN E. \\
BERRIOS \\
\hline
\end{tabular}

para este ser uma categoria descritiva (no sentido tradicional do século XIX), mas também um mecanismo e uma fonte de energia. Surpreendentemente, esta concepção muito estendida de afeto, embora importante para o posterior desenvolvimento da psicanálise, tendia a negligenciar seus aspectos fenomenológicos (Fenichel, 1945).

Perdidos em algum lugar entre os pontos de vista evolucionista, periferialista e psicodinâmico, os distúrbios clínicos do afeto permaneceram mal descritos. Por exemplo, Jaspers (1963) dedicou a eles apenas cinco páginas, que estão entre as menos inspiradas de seu livro.

Bleuler (1906) escreveu em um trabalho inicial sobre os afetos, com alguma sensibilidade, mas o seu tratamento posterior deste tópico tornou-se convencional e superficial (Bleuler, 1934). Bianchi (1906) incluiu em seu livro uma seção grande sobre a sintomatologia dos afetos desordenados, mas o seu tratamento é excessivamente fisiológico. Régis (1906, p. 84) restringiu o papel dos transtornos de humor para o de precipitantes de "delírios e alucinações".

A distinção de Kraepelin (1913) entre a demência precoce e a insanidade maníaco-depressiva parece estar baseada apenas em uma separação psicopatológica entre um distúrbio primário do pensamento e um da afetividade, respectivamente. A análise da oitava edição, na verdade, mostra que ele não incluía "a deficiência primária de afeto" entre os critérios definidores da insanidade maníaco-depressiva. Estes eram (1) prognóstico uniforme e bom; (2) hereditariedade diferencial (p. 1183-1185) e (3) presença de excitação ou inibição primárias (na tradição do século XIX esses dois sintomas se referem a distúrbios de psicomotricidade e não eram necessariamente sinônimos de elação ou depressão, respectivamente) (p. 1370).

Schneider (1959) incluiu na sua Psicopatologia um apêndice curto sobre os "sentimentos anormais" e ressaltou suas polaridades positivas e negativas. Mesmo Minkowski (1966), cuja tarefa autodeterminada era supostamente a do desenvolvimento de uma psicopatologia fenomenológica, produziu uma caracterização quase mecanicista dos transtornos de humor, de acordo com a qual os sintomas poderiam resultar da fraqueza, inibição, disjunção, disritmia e imaturidade da faculdade afetiva. Talvez a análise de Bash (1955) seja a mais séria e relevante para a prática clínica até o presente momento.

Enquanto durante a época dourada da psicopatologia descritiva a destilação pelos grandes clínicos de sua experiência clínica favoreceu sintomas como as alucinações, os delírios, as obsessões, os distúrbios de memória etc., os transtornos do afeto foram persistentemente negligenciados. Este trabalho apontou inúmeros fatores históricos e sugeriu uma hipótese para explicar esse estado de coisas. 


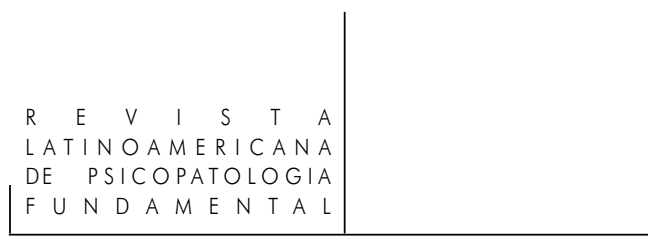

\section{Referências}

Abbagnano, N. Sentimiento. In: Dizionario de filosofia. Turin: Unione TipograficoEditrice Torinese, 1961.

ACKerknecht, E. H. Medicine at the Paris Hospital 1797-1848. Baltimore: Johns Hopkins Press, 1967.

Akiskal, H. S. Dysthymic disorders. American Journal of Psychiatry, n. 140, p. 11-20, 1983.

Albrecht, F.M. A re-appraisal of Faculty Psychology. Journal of the History of Behavioural Science, n. 6, 36-40, 1970.

Alonso, F. Fundamentos de la Psiquiatria Actual. Madrid: Paz Montalvo, 1976. V. 1, p. 263-304.

Arbousse-Bastide, P. Auguste Comte et la folie. In: Les sciences de la folie (ed. R. Bastide). Paris: Mouton, 1972. p. 47-72.

Baguenier-Desormeaux, A. Étude sur le traitement moral et ses Origines philosophiques. Mémoire pour 1e C.E.S. de Psychiatrie. Ronéot: Angers, 1983.

BALAN, B. Sur le rôle de l'imaginaire dans la pratique psychiatrique au XIX siècle. Revue d'histoire des sciences et de leurs applications, n. 25, p. 171-190, 1972.

Barnett, S.A. The "Expression of the Emotions". In: A Century of Darwin. (ed. S. A. Barnett). London: Mercury Books, 1962. p. 206-230.

Barrucard, D. Histoire de l'hypnose en France. Paris: Presses Universitaires de France, 1967.

Barthes, R. Sémiologie et médecine. In: Les sciences de la folie. (ed. R. Bastide). Paris: Mouton, 1972. p. 37-46.

BAsh, K.W. Lehrbuch der allgemeinen Psychopothologie. Grundbegriffe und Klinik. Stuttgart: George Thieme, 1955.

BedFord, E. Emotions. In: Essays in Philosophical Psychology. (ed. D.F. Gustafson). London: Macmillan, 1954. p. 77-98.

Beebe-Center, J.G. Feeling and emotion. In: Theoretical Foundations of Psychology. (ed. H. Helson). New York: Van Nostrand, 1951. p. 142-175.

BERRIOS, G.E. Delirium and confusion in the 19th century: a conceptual history. British Journal of Psychiatry, n. 139, p. 439-449, 1981a. . Stupor: a conceptual history. Psychologycal Medicine, n. 11, p. 677-688, 1981 b. Descriptive psychopathology: conceptual and historical aspects.

Psychological Medicine, n. 14, p. 303-313, 1984a. 


\begin{tabular}{c|c} 
HISTÓRIA DA \\
PSICOPATOLOGIA, \\
POR GERMAN E. \\
BERIOS \\
\hline
\end{tabular}

. Epilepsy and insanity during the 19th century. Archives of Neurology, n. 41, p. 978-981, 1984b.

. 'Depressive pseudodementia' or 'melancholic dementia'? A nineteenth century view. Journal of Neurology, Neurosurgery and Psychiatry, n. 48, p. 393-400, 1985.

Bianchi, L. A Textbook of Psychiatry. London: Baillière Tindall, 1906. p. 343-385.

Bleuler, E. Affektivität, Suggestibilität, Paranoia. Saale: Carl Marhold, 1906. . Textbook of Psychiatry. New York: Macmillan, 1934. p. 117-133.

Bollote, G. Moreau de Tours 1804-1884. Confrontations psychiatriques, n. 11, p. 9$-26,1973$.

Borgese, G.A. Romanticism. Encyclopaedia of the Social Sciences. New York:

Char1es Scribner \& Sons, 1934. V. 13.

Boring, E. G. A history of introspection. Psychological Bulletin, n. 50, p. 169-189, 1953.

Brentano, F. Psychology from an Empirical Standpoint. Transl. A.C. Rancurello; D.B. Terrell; L. L. McAlister. London: Routledge and Kegan Paul, 1973. p. 235-364.

BRICKE, J. Hume's associationistic psychology. Journal of the History of Behavioural Science, n. 10, p. 397-409, 1974.

Brooks, G.P. The Faculty Psychology of Thomas Reid. Journal of the History of Behavioural Science, n. 12, p. 65-77, 1976.

Broussais, F.J.U. De l'irritation et de la folie. Paris: Delaunay, 1828.

Buchner, E.F. A study of Kant's psychology. The Psychological Review Monograph, Suppl. 4, p. 77-87, 1897.

Bucknill, J.C.; Tuke, D.H. A Manual of Psychological Medicine. London: John Churchill, 1858.

Burton, R. The Anatomy of Melancholy. London: Chatto and Windus, 1883.

Bynum, W.F. Rationales for therapy in British psychiatry 1780-1835. Medical History, n. 18, p. 317-334, 1964.

. Varieties of Cartesian experience in early 19th century neurophysiology. In:

Philosophical Dimensions of the Neuro-medical Sciences. (ed. S. F. Spicker and T.

Engelhardt Jr). Dordrecht: Reidel, 1976. p. 15-33.

CAnToR, G. N. Phrenology in early 19th century Edinburgh: an historiographical discussion. Annals of Science, n. 32, p. 195-218, 1975.

CARLSOn, E.T.; Dain, N. The psychotherapy that was moral treatment. American Journal of Psychiatry, n. 117, p. 519-524, 1960. 
Carpenter, W.B.; Power, H. Principles of Human Physiology. 8. ed. London: J. \& A. Churchill, 1876.

Chaslin, P. Eléments de sémiologie et de clinique mentale. Paris: Asselin et Houzeau, 1912.

Claparède, E. Feelings and emotions. In: Feelings and Emotions. (ed. M. L. Reymert). New York: Clark University Press, 1928. p. 124-138.

Colloque International de Bruxelles. Folie et déraison à la Renaissance. Brussels: Editions de l'Université de Bruxelles: Brussels, 1976.

Colonna D'IstRa, F. L'influence du moral sur la physique d'après Cabanis et Maine de Biran. Revue de métaphysique et de morale, n. 21, p. 451-461, 1913.

Condillac, E. B. de. Traité de sensations. In: Oeuvres philosophiques de Condillac. Paris: Presses Universitaires de France, 1947. V. 1.

Conry, Y. Thomas Willis ou le premier discours rationaliste en pathologie mentale. L'information psychiatrique, n. 58, p. 313-323, 1982.

Cooter, R.J. Phrenology and British alienists, c. 1825-1845. Medical History, n. 20, p. 1-21, 135-151, 1976.

Coupland, W.C. Philosophy of mind. In: A Dictionary of Psychological Medicine. (ed. D. H. Tuke). London: J. \& A. Churchill, 1892. V. I, p. 27-49.

CRICHTOn, A. Sir. An Inquiry into the Nature and Origin of Mental Derangement. London: Cadell and Davies, 1798. 2 vols.

DANZinger, K. The history of introspection reconsidered. Journal of the History of Behavioural Science, n. 16, p. 241-262, 1980.

Darwin, C. The Expression of the Emotions in Man and Animals. London: John Murray, 1872.

Deerborn, G.U.N. The concept of psychogenesis. Journal of Abnormal Social Psychology, n. 32, p. 207-217, 1937.

Delacroix, M.H. Maine de Biran et l'école médico-psychologique. Bulletin de la Société française de philosophie, n. 24, p. 51-63, 1924.

Delasiauve, L.J.F. Du diagnostic differentiel de la hypémanie. Annales médicopsychologiques, n. 3, p. 380-442, 1851.

. Psychologie de la sensibilité: sentiments, etc. Journal de médecine mentale, n. 1, p. 230-236, 1861.

Deleule, D. La psychologie. Mythe scientifique. Paris: Robert Laffont, 1969.

Delkeskamp, C. Philosophica1 reflexions in the 19th century medico-legal discussions. In: Mental Health: Philosophical Perspective (ed. H. T. Engelhardt, Jr and S. F. Spicker). Dordrecht: Reidel, 1977. p. 125-137. 


\begin{tabular}{c|c} 
HISTÓRIA DA \\
PSICOPATOLOGIA, \\
POR GERMAN E. \\
BERIOS \\
\hline
\end{tabular}

Descartes, R. The passions of the soul. In: The Philosophical Works. Transl. E. S. Haldane and G. R. T. Ross. Cambridge: Cambridge University Press, 1967. p. 329-427.

Dewhurst, K. Willis's Oxford Lectures. Oxford: Sandford Publications, 1980.

DodDs, E.R. The Greeks and the Irrational. California: University of California Press, 1951.

Donegan, A. Wittgenstein on sensation. In: Wittgenstein (ed. G. Pitcher). London: Macmillan, 1968. p. 324-351.

Drabkin, I. E. Remarks on ancient psychopathology. Isis, n. 46, p. 223-234, 1955.

Drovet, A. Maine de Biran. Paris: Presses Universitaires de France, 1968.

Ellenberger, H. The Discovery of the Unconscious. London: Allen Lane, 1970.

ERrera, P. Some historical aspects of the concept of phobia. Psychiatric Quarterly, n. 36, p. 325-336, 1962.

Erwin, E. Behaviour Therapy. Scientific, Philosophical and Moral Foundations. Cambridge: Cambridge University Press, 1978.

Esquirol, E. De la lypémanie ou mélancholie. (ed. P. Fédida and J. Postel). Paris: Sandoz Editions, 1976.

. Des passions considérées comme causes, symptomes el moyens curatifs de l'aliénation mentale. Paris: Librairie des Deux-Mondes, 1980.

Evans, B. The Psychiatry of Robert Burton. New York: Columbia University Press, 1944.

Ey, H. La notion de "maladie morale" et le "traitement moral" dans la psychiatrie française et allemande du début du XIXe siècle. Perspectives psychiatriques, n. 1, p. 12-13, 1978.

FALRET, J.P. Leçons cliniques de médecine mentale - Vol. I. Symptomatologie générale des maladies mentales. Paris: Baillière, 1854.

. De la non-existence de la monomanie (1854). In: Des maladies mentales et des asiles d'aliénés. Paris: Baillière, 1864. p. 425-448.

. Discussion sur la folie raisonante. Annales médico-psychologiques, n. 24, p. 382-426, 1866.

FANCHER, R.E. Brentano's psychology from an empirical standpoint and Freud's early metapsychology. Journal of the History of Behavioural Science, n. 13, p. 207-227, 1977.

Fellner von FeldegG, F. Beiträge zur philosophie des Gefühls; gesammelte kritischdogmatische Aufsätze über zwei Grundproblemen. Leipzig: Barth, 1900.

Fenichel, O. The Psychoanalytical Theory of Neurosis. London: Kegan, Paul, Trench, Trubner, 1945.

Rev. Latinoam. Psicopat. Fund., São Paulo, v. 15, n. 1, p. 138-170, março 2012 
Feuchtersleben, E. von. The Principles of Medical Psychology. Transl. H.E. Lloyd and B.G. Babington). London: Sydenham Society, 1847.

Fischer-Homberger, E. On the medical history of the doctrine of imagination. Psychological Medicine, n. 9, p. 619-628, 1979.

Flashar, H. Melancholie und Melancholiker in den medizinischen Theorien der Antike. Berlin: W. D. Gruyter, 1966.

Fodor, J.A. The Modularity of Mind. Cambridge, Mass.: MIT Press, 1983.

FonseCA, A.F. da. Affective equivalents. British Journal of Psychiatry, n. 109, p. 464$-469,1963$.

Fortenbaugh, W.W. Aristotle on Emotion. London: Academic Books, 1975.

Foucault, M. Maladie mentale et psychologie. Paris: Presses Universitaires de France, 1954.

. Histoire de la folie à l'âge classique. Paris: Gallimard, 1972.

Fulcher, J.R. Puritans and the passions: the faculty psychology in American Puritanism. Journal of the History of Behavioural Science, n. 9, p. 123-139, 1973.

Gangler-Mundwiller, D. Mélancolie et Désespérance. Médecine et morale au quinzième siècle. In: La mélancolie dans la relation de l'âme et du corps. L.M.S. n.1, Université de Nantes, 1979.

Gardair, J. Philosophie de St. Thomas: les passions et la volonté. Paris: Lethielleux, 1892.

Gardiner, H.M. The definition of feeling. Journal of Philosophy, Psychology and Scientific Method, n. 3, p. 57-62, 1906.

Gardiner, H.M.; Metcalf, R.C.; Beebe-Center, J.G. Feeling and Emotion. A History of Theories. New York: American Book Company, 1937.

Gelder, M.G. Is cognitive therapy effective? Discussion Paper. Journal of the Royal Society of Medicine, n. 76, p. 938-942, 1983.

GiUdicelLI, S. Le concept d'angoisse. L'évolution psychiatrique, n. 48, p. 657-673, 1983.

Green, A. Le discours vivant. Paris: Presses Universitaires de France, 1973. $-156,1977$.

Conceptions of affect. International Journal of Psychoanalysis, n. 58, p. 129-

Griesinger, W. Mental Pathology and Therapeutics. London: New Sydenham Society, 1867. p. 63-66.

Gruber, H. E. Darwin on Man. 2nd ed. Chicago: University of Chicago Press, 1981.

Hamilton, M. Fish's Clinical Psychopathology. Bristol: John Wright, 1974. p. 65-76.

Rev. Latinoam. Psicopat. Fund., São Paulo, v. 15, n. 1, p. 138-170, março 2012 


\begin{tabular}{c|c} 
HISTÓRIA DA \\
PSICOPATOLOGIA, \\
POR GERMAN E. \\
BERRIOS \\
\hline
\end{tabular}

Harrow, M.; Grinker, R.R.; Ho1zman, P.S.; Kayton, L. Anhedonia and schizophrenia. American Journal of Psychiatry, n. 134, p. 794-797, 1977.

Hartley, D. Observations on Man, his Frame, his Duty and his Expectations. 6th ed. London: Thomas Tegg and Son, 1834.

Hécaen, H.; Lanteri-Laura, G. Évolution des connaissances et des doctrines sur les localisations centrales. Paris: Desclée de Brouwer, 1977.

HeIBERG, J.L. Geisteskrankheiten im klassischen Altertum. Allegemeine Zeitschrift für Psychiatrie, n. 86, p. 1-44, 1927.

Heinroth, J.C. Textbook of Disturbances of Mental Life. Transl. J. Schmorak. Baltimore: Johns Hopkins University Press, 1975. V. I.

Hilgard, E.R. The trilogy of mind: cognition, affection and conation. Journal of the History of Behavioural Science, n. 16, p. 107-117, 1980.

Hoeldtke, R. The history of associationism and British medical psychology. Medical History, n. 11, p. 46-64, 1967.

HöFfDing, H. Outlines of Psychology. Transl. M. E. Lowndes. London: Macmillan, 1892. p. 221-307.

Hollander, B. The Mental Functions of the Brain. An Investigation into their Localization and their Manifestation in Health and Disease. London: Grant Richards, 1901.

JACKSON, S.W. Unusual mental states in mediaeval Europe. I: Medical syndromes of mental disorder 400-1100 A.D. Journal of History of Medicine and Allied Science, $\mathrm{n}$. 27, p. 262-297, 1972.

. Two sufferers' perspectives on melancholia: 1690s to 1790s. In: Essays in the History of Psychiatry. (ed. E.R. Wallace IV and L.C. Pressley). W.M.S. Hall Psychiatric Institute of the South Carolina Department of Mental Health, 1980. p. 59-71.

. Melancholia and partial insanity. Journal of the History of Behavioural Science, n. 19, p. 173-184, 1983a.

. Melancholia and mechanical explanation in eighteenth century medicine. Journal of History of Medicine and Allied Sciences, n. 38, p. 298-319, 1983b.

JAMES, W. The Principles of Psychology. London: Macmillan, 1891. V. 2, p. 442-485.

JACQUES, A. Facultés de l'âme. In: Dictionnaire des sciences philosophiques. 2nd ed. (ed. A. Franck). Paris: Hachette, 1875. p. 511-516.

JASPERs, K. General Psychopathology. Transl. M. Hamilton and J. Hoenig). Manchester: Manchester University Press., 1963. p. 108-117.

JobE, T. H. Medical theories of melancholia in the 17 th and early 18 th centuries. Clinico-Medica, n. 11, p. 217-229, 1976. 
Kageyama, J. Sur l'histoire de la monomanie. L'évolution psychiatrique, n. 49, p. 155$-162,1984$.

Kenny, A. Action, Emotion and Will. London: Routledge, Kegan \& Paul, 1963. . Descartes. New York: Random House, 1968.

Ketal, R. Affect, mood, emotion and feeling. Semantic consideration. American Journal of Psychiatry, n. 132, p. 1215-1217, 1975.

KING, L.S. Signs and symptoms. Journal of the American Medical Association, n. 206, p. 1063-1065, 1968.

KLEIN, D.B. The Scottish School and its "Faculties". In: A History of Scientific Psychology. London: Routledge, Kegan \& Paul, 1970. Chapter 19, p. 638-698.

KoH, S.E.; Grinker, R.R.; Marusartz, N.T.; Forman, P. Affective memory and schizophrenic anhedonia. Schizophrenia Bulletin, n. 7, p. 292-307, 1981.

Koninck, C. de. Introduction à l'étude de l'âme. Lavel théologique et philosophique, n. 3, p. 9-65, 1947.

Kowalewski, P.J. Sur la curabilité de la démence. Annales médico-psychologiques, n. 44, p. 40-53, 1886.

Kraepelin, E. Psychiatrie. Ein Lehrbuch für Studieren und Ärzte. 8th ed. Leipzig:

Barth, 1913. V. 3.

Kroll, J. A reappraisal of psychiatry in the Middle Ages. Archives of General Psychiatry, n. 29, p. 276-283, 1973.

Krueger, F. Das Wesen der Gefühle. Entwurf einer systematischen Theorie. Archiv für die Gesamte Psychologie, n. 65, p. 91-128, 1928.

LAder, M. The Psychophysiology of Mental Illness. London: Routledge and Kegan Paul, 1975.

Laín Entralgo, P. Historia de la medicina. Barcelona: Salvat, 1978.

Landman, M. Philosophische Anthropologie. Berlin: Gruyter, 1958.

Lanteri-Laura, G. Histoire de la phrénologie. Paris: Presses Universitaires de France, 1970.

. La chronicité dans la psychiatrie moderne française. Note d'histoire théorique et sociale. Annales, n. 3, p. 548-568, 1972.

Laplanche, J.; Pontalis, J-B. (eds.). Affect. In: The Language of Psychoanalysis. London: The Hogarth Press, 1973. p. 13-14.

LaYcock, T. A Treatise on the Nervous Diseases of Women. London: Longman, Orme, Brown, Green and Longmans, 1840. . Mind and Brain: or the Correlations of Consciousness and Organization. 


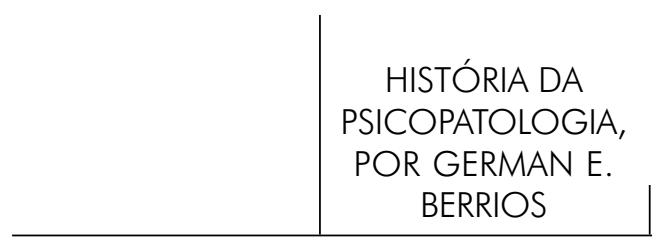

Edinburgh: Sutherland and Knox, 1860. V. 1, p. 76-107.

LEARY, D.E. The philosophical developments of the conception of psychology in Germany 1780-1850. Journal of the History of Behavioural Science, n. 14, p. 113-121, 1978.

LEEPER, R.W. A motivational theory of emotion to replace emotion as disorganized response. Psychological Review, n. 55, p. 5-21, 1948.

LESSER, I.M.; LeSSER, B.Z. Alexithymia: examining the development of a psychological concept. American Journal of Psychiatry, n. 140, p. 1305-1308, 1983.

Lewes, G.H. Comte's Philosophy of the Sciences. London: George Bell and Sons, 1878.

LEwIS, A. Problems presented by the ambiguous word "anxiety" as used in psychopathology. Israel Annals of Psychiatry and Related Disciplines, n. 5, p. 105$-121,1967$.

. "Psychogenic": a word and its mutations. Psychological Medicine, n. 2, p. 209-215, 1972.

Liebowitz, M.R.; Klein, D.F. Hysteroid dysphoria. Psychiatric Clinics of North America, n. 2, p. 555-575, 1979.

Lloyd, G.E.R. Aristotle: The Growth and Structure of his Thought. Cambridge:

Cambridge University Press, 1968.

Locke, J. An Essay Concerning Human Understanding (1959 edn consulted; collated and annotated by A.C. Fraser). New York: Dover, 1690.

Lopez Piñero, J.M. Historical Origins of the Concept of Neurosis. Transl. D. Berrios. Cambridge: Cambridge University Press, 1983.

Lovejoy, A.O. The Great Chain of Being. New York: Harper Torchbrook, 1960. p. 287-314.

LuYs, J. Des obsessions pathologiques dans leur rapports avec l'activité automatique des éléments nerveux. L'Encéphale, n. 3, p. 20-61, 1883.

MacDonald, M. Mystical Bedlam. Madness, Anxiety and Healing in Seventeenth Century England. Cambridge: Cambridge University Press, 1981.

MackenzIE, B. Darwinism and positivism as methodological influences on the development of psychology. Journal of the History of Behavioural Science, n. 2, p. 330-337, 1976.

McMahon, C.E. The role of imagination in the disease process: pre-Cartesian history (the role of imagination in the disease process). Psychological Medicine, n. 6, p. 179$-184,1976$.

Mairet, A. De la démence mélancolique. Paris: Masson, 1883.

Mantegazza, P. Fisionomia e mimica. (English translation: Physiognomy and Expression no date). London: Walter Scott, 1878.

Rev. Latinoam. Psicopat. Fund., São Paulo, v. 15, n. 1, p. 138-170, março 2012 
Meyer, A. The frontal lobe syndrome, the aphasias and related conditions. A contribution to the history of cortical localization. Brain, n. 97, p. 565-600, 1974.

Minkowski, E. (1966). Traité de psychopathologie. Paris: Presses Universitaires de France, 1966.

Mischel, T. Affective concepts in the psychology of J. F. Herbart. Journal of the History of Behavioural Science, n. 9, p. 262-268, 1973.

Monahan, W.B. The Psychology of St. Thomas Aquinas. Worcester: Ebenezer Baylis and Son, 1935.

Morel, B.A. Traité des maladies mentales. Paris: Masson, 1860.

. Du délire émotif névrose du système nerveux ganglionaire visceral. Archives générales de médecine (6th series), n. 7, p. 385-402, 530-551, 700-707, 1866.

Morgan, C. L. An Introduction to Comparative Psychology. London: Walter Scott, 1903.

Neugebauer, R. Mediaeval and early modern theories of mental illness. Archives of General Psychiatry, n. 36, p. 477-483, 1979.

Noel, P.S.; Carlson, E.T. The Faculty Psychology of Benjamin Rush. Journal of the History of Behavioural Science, n. 9, p. 369-377, 1973.

Owens, H.; Maxmen, J.S. Mood and affect: a semantic confusion. American Journal of Psychiatry, n. 136, p. 97-99, 1979.

Piaget, J. Intelligence and Affectivity: Their Relationship During Child Development. Transl. and ed. T.A. Brown and C.E. Kaegi. Berkeley: University of California, 1981.

Pigeaud, J.M. Le rôle des passions dans la pensée médicale de Pinel à Moreau de Tours. History and Philosophy of the Life Sciences, n. 2, p. 123-140, 1980.

. La maladie de l'âme. Étude sur la relation de l'âme et du corps dans la tradition médico-philosophique antique. Paris: Les Belles Lettres, 1981.

Pinel, P. Traité médico-philosophique sur l'aliénation mentale. 2nd ed. Paris: J.A. Brosson, 1809.

Pistoia, L. del. Le problème de la temporalité dans le psychiatrie française classique. L'Évolution psychiatrique, n. 36, p. 445-474, 1971.

Pollit, J. Moodiness: a heavenly problem? Journal of the Royal Society of Medicine, n. 75, p. 7-16, 1982.

Postel, J. Naissance et decadence du traitement moral pendant la première moitie du $\mathrm{XIX}^{\mathrm{e}}$ siècle. L'évolution psychiatrique, n. 44, p. 585-616, 1979.

Prichard, J.C. A Treatise on Insanity. London: Sherwood, Gilbert and Piper, 1835.

Rancurello, A.C. A Study of Franz Brentano. New York: Academic Press, 1968. 


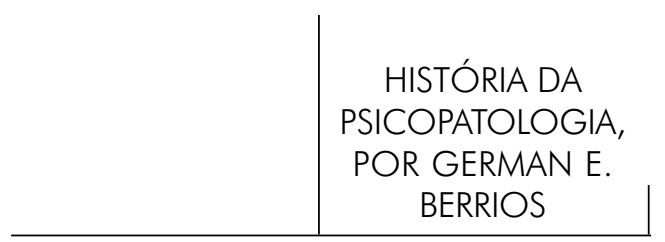

RÉGIS, E. Précis de psychiatrie. Paris: Octave Doin, 1906.

ReID, T. Essays on the Active Powers of the Human Mind (introduction by B. Brody). Cambridge, Mass.: MIT Press, 1969.

Riвот, T. The Psychology of Emotions. London: Walter Scott, 1897.

Richards, R.J. Lloyd Morgan's theory of instinct: from Darwinism to neo-Darwinism. Journal of the History of Behavioural Science, n. 13, p. 12-32, 1977.

RIESE, W. The impact of nineteenth century thought on psychiatry. International Record of Medicine, n. 173, p. 7-19, 1960.

. La théorie des passions à la lumière de la pensée médicale du XVII siècle.

New York: Bale, 1965.

Roccatagliata, G. Storia della psichiatria antica. Milan: Ulrico Hoepli, 1973. . Le origini della psychoanalisi nella culture classica. Rome: Il Pensiero Scientifico, 1891.

Rochoux, M. Psychologie. In: Dictionnaire de médecine. 2nd ed. Paris: Labé, 1842. V. 26, p. 280-317.

Rosen, G. The philosophy of ideology and the emergence of modern medicine in France. Bulletin of the History of Medicine, n. 2, p. 328-339, 1946.

. Irrationality and madness in seventeenth and eighteenth century Europe. In: Madness in Society (ed. G. Rosen). Chicago: University of Chicago Press, 1968. p. 151-171.

. Nostalgia: a "forgotten" psychologica1 disorder. Psychological Medicine, n. 5, p. 340-354, 1975.

Rosmini Serbati, A. Psychology. London: Kegan Paul Trench and Co., 1888. V. 3, p. 174-189.

Ross, E.D.; Mesulam, M.M. Dominant language functions of the right hemisphere? Prosody and emotional gesturing. Archives of Neurology, n. 36, p. 144-148, 1979.

Rush, B. Lectures on the Mind (edited, annotated and introduced by E. T. Carlson; J. L. Wollock and P. S. Noel). Philadelphia: American Philosophica1 Society, 1981.

RyLe, G. The Concept of Mind. London: Hutchinson, 1949. p. 83-115.

Sarantoglou, G. Quelques réflexions "psychopathologiques" et "psychothérapeutiques" à propos de la folie de l'ajax sophocléen. In: Les thérapeutiques de l'âme. L.M.S. n. 2, Université de Nantes, 1980.

SARTRe, J. P. Esquisse d'une théorie des émotions. Paris: Hermann, 1939.

SAss, H. Affektdelite. Nervenarzt, n. 54, p. 557-575, 1983. 
SAURI, J.J. Historia de las ideas psiquiátricas. Buenos Aires: Lohlé, 1969.

SCHACHTER, S.; Singer, J.E. Cognitive, social and physiological determinants of emotional state. Psychological Review, n. 69, p. 377-399, 1962.

Scharfetter, C. General Psychopathology. Cambridge: Cambridge University Press, 1980. p. 232-247.

SCHELER, M. Wesen und Formen der Sympathie. Bonn: Cohen, 1923.

SCHNEIDER, K. Clinical Psychopathology. New York: Grune and Stratton, 1959. p. 145$-166$.

Schwartz, L. Les névroses et la psychologie dynamique de Pierre Janet. Paris:

Presses Universitaires de France, 1955.

Simmonnet, J. Folie et notations psychopathologiques dans l'oeuvre de saint Thomas d'Aquin. In: Nouvelle histoire de la psychiatrie. (ed. J. Postel and C. Quétel). Paris: Privat, 1983. p. 55-73.

Simon, B.B. Models of mind and mental illness in Ancient Greece: II. The platonic model. Journal of the History of Behavioural Science, n. 8, p. 389-404 ; n. 9, p. 3-17, 1972-19733.

Simon, B. Mind and Madness in Ancient Greece. Ithaca: Cornell University Press, 1978.

Siomopoulos, V. The Structure of Psychopathological Experience. New York: Brunner/Mazel, 1983.

Solmsen, F. Plato and the concept of the soul (psyche): some historical perspectives. Journal of the History of Ideas, n. 44, p. 355-364, 1983.

Soury, J. Des doctrines psychologiques contemporaines. L'Encéphale, n. 3, p. 61-85, 1883.

Starobinski, J. Historia del tratamiento de la melancholia desde los origenes hasta 1900. Acta Psychosomatica (Basle), n. 3, 1962.

. The word "reaction": from physics to psychiatry. Psychological Medicine, n. 7, p. 373-386, 1977.

StöRring, G. Mental Pathology in its Relation to Normal Psychology. London: Swan Sonnenschein, 1907.

Swain, G. L'Aliéné entre le médecine et le philosophie. Perspectives psychiatriques, n. 65, p. 90-98, 1978.

Tissot, M. Les passions. Influence du moral sur le physique. Annales médicopsychologiques, n. 6, p. 157-171, 1865. 


\begin{tabular}{c|c} 
HISTÓRIA DA \\
PSICOPATOLOGIA, \\
POR GERMAN E. \\
BERRIOS \\
\hline
\end{tabular}

TizARD, B. Theories of brain localization from Flourens to Lashley. Medical History, n. 3, p. 132-145, 1959.

WaLker, N. Crime and Insanity in England. Vol. I: Historical Perspective. Edinburgh: The University Press, 1968. p. 35-51.

WARD, J. Psychology. Encyclopaedia Britannica, 1889. p. 37-85.

. Psychological Principles. Cambridge: Cambridge University Press, 1918.

p. 243-285.

Warren, H.C. History of the Association Psychology. New York: Scribner and Sons, 1921.

Washburn, M.F. The term "feeling". Journal of Philosophy, Psychology and

Scientific Method, n. 3, p. 62-63, 1906.

Watson, C.G.; KLETT, W.G.; LoREI, T.W. Toward an operational definition of anhedonia. Psychological Report, n. 26, p. 371-376, 1970.

Weckowicz, T.E.; Liebel-Weckowicz, H. Typologies of the theory of behaviourism since Descartes. Sudhoffs Archiv., n. 66, p. 129-151, 1982.

Weiskrantz, L. (ed.). Emotion. In: Analyses of Behavioural Change. New York:

Harper and Row, 1968. p. 50-90.

Werlinder, H. Psychopathy: A History of the Concept. Uppsala: Acta Universitatis Upsaliensis, 1978.

White, A. R. The Philosophy of Mind. New York: Random House, 1967. p. 105-130.

WundT, W. Outlines of Psychology. Transl. C.H. Judd. Leipzig: Wilhelm Engelmann, 1897.

Young, R. M. Mind, Brain and Adaptation in the 19th century. Oxford: Clarendon Press, 1970.

Zienen, T. Introduction to Physiological Psychology. Transl. C. C. Van Liew and O.

W. Beyer). London: Swan Sonnenschein, 1909.

\section{Resumos}

(The Psychopathology of Affects: Conceptual and Historical Aspects)

Disorders of the affects have contributed little to the diagnostic definition of mental illness, and their phenomenological description never attained the stature of the psychopathologies of perception or of cognition. This article shows how the subordinate role played by the affects in the Western conception of man led to an original but persistent perspective of mental illness as an exclusive disorder of the intellect. Attempts by 19thcentury psychiatrists to contest this notion were only partially successful because of the difficulties in the conceptual handling of most emotional behaviors and the terminologi- 
cal redundancy that this engendered. These efforts were frustrated by the rise of associationism, the emergence of experiments on cerebral locations, the peripheral definition of the emotions and, finally, by the development of Darwinism. As a result, no autonomous psychopathology of the affects was ever developed. In addition, the eventual recognition of the so-called "primary" humor disorders failed to lead to a refinement in the semiology of the experiments carried out. This process was greatly hampered by the use of descriptive behavioral substitutes or by metapsychological descriptions of the affects as a form of energy or as a drive. None of these developments contributed to a clinical description of the disorders of humor.

Key words: Disorders of humor - history, psychopathology - history, psychology history, emotions

(La psychopathologie de l'affectivité: aspects conceptuels et historiques)

Les troubles de l'affect n'ont pas beaucoup contribué à la définition du diagnostic de la maladie mentale et sa description phénoménologique n'a jamais atteint la richesse de la psychopathologie de la perception ou de la cognition. Cet article montre comment le rôle subalterne joué par l'affectivité dans la conception occidentale de l'homme conduit à une vision initiale, mais persistante, de la maladie mentale comme un trouble exclusif de l'intellect. Les tentatives faites par les psychiatres du XIXe siècle pour contester cette notion n'ont que partiellement abouti en raison des difficultés concernant la manipulation conceptuelle des comportements affectifs et de la redondance terminologique qu'elle engendre. Ces efforts ont été frustrés par la renaissance de l'associationnisme, l'apparition des expériences de localisation cérébrale, la définition périphéraliste des émotions et enfin par le développement du darwinisme. En conséquence, une psychopathologie autonome de l'affectivité n'a jamais été développée. La reconnaissance éventuelle des troubles dits "primaires» de l'humeur n'a cependant pas engendré un raffinement de la sémiologie des propres expériences. Cela a été empêché par l'utilisation de substituts descriptifs comportementaux ou par de descriptions métapsychologiques de l'affect comme une forme d'énergie ou comme une force pulsionnelle. Aucun de ces développements n'a contribué à la description clinique des troubles de l'humeur.

Mots clés: Troubles de l'humeur - histoire, psychopathologie - histoire, psychologie histoire, émotion

(La psicopatologia de la afectividad: aspectos conceptuales e históricos)

Los trastornos del afecto no contribuyeron mucho para la definición diagnóstica de la enfermedad mental, y su descripción fenomenológica nunca alcanzó la riqueza de la psicopatologia de la percepción o de la cognición. Este artículo muestra como el papel subordinado desempeñado por la afectividad en la concepción occidental del hombre condujo a una visión inicial, pero persistente, de la enfermedad mental como 


\begin{tabular}{c|c} 
HISTÓRIA DA \\
PSICOPATOLOGIA, \\
POR GERMAN E. \\
BERRIOS \\
\hline
\end{tabular}

un disturbio exclusivo del intelecto. Las tentativas de los psiquiatras del siglo XIX de cuestionar esa noción fueron, apenas parcialmente, exitosas debido a las dificultades de manejo conceptual de la mayor parte de los comportamientos afectivos y de la redundancia terminológica que eso engendraba. Esos esfuerzos fueron frustrados por el renacimiento del Asociacionismo, del surgimiento de los experimentos de localización cerebral, por la definición periferialista de las emociones y, finalmente, por los desdoblamientos del darwinismo. Como resultado no se desarrolló ninguna psicopatologia autónoma de la afectividad. El reconocimiento eventual de los así llamados trastornos "primarios" del humor no llevó, sin embargo, a un refinamiento en la semiologia de las propias experiencias. Eso fue impedido por el uso de subtitutivos descriptivos comportamentales o por descripciones metapsicológicas del afecto como una forma de energia o como una fuerza pulsional. Ninguno de esos desarrollos contribuyó para la descripción clínica de los trastornos del humor.

Palabras clave: Trastornos del humor - historia, psicopatologia - historia, psicologia historia, emociones

(Die Psychopathologie des Affektes: Begriffliche und historische Aspekte)

Die Affektstörungen haben nicht sehr zur diagnostischen Definition von Geisteskrankheit beigetragen und ihre phänomenologische Beschreibung hat nie den Reichtum der Wahrnehmungs- oder der Erkenntnispsychopathologie erreicht. In diesem Beitrag wird die zweitrangige Rolle des Affektes in der westlichen Auffassung des Menschen gezeigt und inwiefern dies zu einer anfänglichen aber anhaltenden Annahme geführt hat, dass die Geisteskrankheit ausschließlich eine Störung des Intellektes ist. Die Versuche der Psychiater des 19. Jahrhunderts, diese Auffassung zu widerlegen, sind nur teilweise gelungen. Zum einen ist dies auf die Schwierigkeiten zurückzuführen, mit den Begriffen der meisten affektiven Verhalten umzugehen und der daraus hervorgehenden terminologischen Redundanzen. Diese Bemühungen wurden vom erneuten Aufkommen des Assoziationismus frustriert, das Aufkommen der Experimente mit der Schädellehre, die verhaltensbasierende Definition der Emotionen und, schließlich, durch die Entwicklungen infolge des Darwinismus. Folglich wurde keine eigenständige Psychopathologie des Affektes entwickelt. Die etwaige Anerkennung der sogenannten „primären” Gemütsstörungen hat jedoch nicht zu einer Präzisierung der Semiologie der eigenen Erfahrungen geführt. Dies wurde durch die Verwendung von Ersatzbegriffen für Verhaltensweisen oder durch metapsychologische Beschreibungen des Affektes als eine Energieform oder Triebkraft verhindert. Keine dieser Entwicklungen hat zur klinischen Beschreibung der Gemütsstörungen beigetragen.

Schlüsselwörter: Gemütsstörungen - Geschichte; Psychopathologie - Geschichte; Psychologie - Geschichte; Emotionen.

Rev. Latinoam. Psicopat. Fund., São Paulo, v. 15, n. 1, p. 138-170, março 2012 


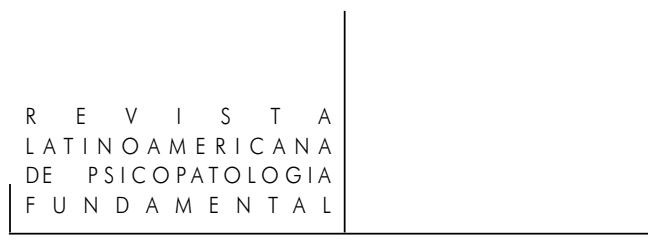

Citação/Citation: BerRios, G.E. A psicopatologia da afetividade: aspectos conceituais e históricos. Revista Latinoamericana de Psicopatologia Fundamental, São Paulo, v. 15, n. 1, p. 138170, março 2012.

Editor do artigo/Editor: Prof. Dr. Manoel Tosta Berlinck

Recebido/Received: 23.4.2011 / 4.23.2011 Aceito/Accepted: 28.7.2011 / 7.28.2011

Copyright: () 2009 Associação Universitária de Pesquisa em Psicopatologia Fundamental/ University Association for Research in Fundamental Psychopathology. Este é um artigo de livre acesso, que permite uso irrestrito, distribuição e reprodução em qualquer meio, desde que o autor e a fonte sejam citados/This is an open-access article, which permits unrestricted use, distribution, and reproduction in any medium, provided the original author and source are credited.

Financiamento/Funding: $\mathrm{O}$ autor declara não ter sido financiado ou apoiado/The author has no support or funding to report.

Conflito de interesses/Conflict of interest: $O$ autor declara que não há conflito de interesses/The author declares that has no conflict of interest.

\section{German E. Berrios}

Médico e filósofo pela Universidad Nacional de San Marcos, Lima, Peru; Psiquiatra; Neurologista; Psicólogo; Filósofo; Historiador e Filósofo da ciência (Oxford University, England); Professor de Neuropsiquiatria e de Epistemologia da Psiquiatria (University of Cambridge, England), desde 1976; Neuropsiquiatra e Chefe do Departamento de Neuropsiquiatria do Hospital Addenbrooke, University of Cambridge, por 32 anos; Coordenador do Comitê de Ética em Pesquisa com Humanos na mesma universidade, por 20 anos; Editor Responsável de History of Psychiatry; Autor de 14 livros, incluindo The History of Mental Symptoms, Descriptive Psychopathology since 19th Century (Prêmio Nacional BMA, 1997), A History of Clinical Psychiatry (com Roy Porter), e Delirio (com F. Fuentenebro) e mais de 400 artigos e capítulos de livros; Membro do Royal College of Psychiatrists; da Associação Britânica de Psicologia e da Academia Britânica de Ciências Médicas; Membro Vitalício do Robinson College, Cambridge; doutor Honoris-Causa da Universidade de Heidelberg (Alemanha), da Universidade Nacional Mayor de San Marcos (Peru) e da Universidad Autónoma de Barcelona (Espanha); Grão Oficial da Ordem del Sol (Condecoração do Governo Peruano, 2007); prêmio Ramon y Cajal 2008 concedido pela Asociación Internacional de Neuropsiquiatria.

University of Cambridge

Box 189, Hills Road

Cambridge,

UK CB2 2QQ

e-mail: geb11@cam.ac.uk 